\title{
UITTREKSEL UIT EEN VERSLAG OVER DEN HANDEL VAN NEW-YORK IN 1865.
}

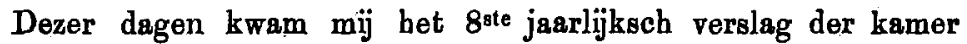
van koophandel te New.York in handen. Het wekte mijne belangstelling en ik meende dat het mededeelingen bevat waarran het der moeite waard kon zijn eenig uittreksel te geven, vooral wat betreft den toestand van New-Yorks handel gedurende den laatsten Amerikaanschen strijd, in vergelijking met de jaren voór, en het eerste jaar na dien oorlog.

De kamer van koophandel van New-York is een der oudste corporatiën van dien aard; zij is den $5^{\text {den }}$ April 1768 gesticht door John Cruger en bestond dus reeds bijna 20 jaren vóór het uitbreken van den Noord-Amerikaanschen onaf hankelijkheidsoorlog. Zij heeft meer het karakter van eene vrije handelssocieteit dan van eene corporatie, zooals men ze in Europa kent. Hare leden worden door de kamer zelve gekozen en waren op 1 Mei 11.919 in getal. Elk hunner draagt jaarlijks 10 dollars bij voor de uitgaven der kamer en heeft daarvoor het gebruik van hare zalen en boekerij. Een eigen gebouw bezit de kamer niet, maar zij wenscht zeer or een te verkrijgen en onderzoekt darrvoor de plannen. Fene som van 1 millioen doll. zou hierroor noodig zijn, maar een der ontwerpers meent dat men zeer goed een 25 personen zal kunnen vinden die elk 10,000 doll., een 50 , die elk 5.000 doll. en een 500 personen die elk 1000 doll. willen geven, en dan is het geld er.

De kamer vergadert geregeld den eersten Donderdag van elke maand, maar houdt ook soms buitengewone vergaderingen, zoodat zij van Mei 1865 tot Mei 1866 in het geheel 18 maal bijeen kwam. Deze werden bijgewoond door een 30 leden, meer dan 30 waren er zelden; 9 leden zijn noodig tot het constitueeren van eene vergadering. Maar de kamer heeft aan verschillende commités de behandeling van eenige zaken opgedragen, welke onder haar ressorteren. Behalve een "executive committee ", een „committee of Bisec. Eicon. 1867. 
arbitration" en de verschillende commités voor elke afzonderlijke zaak van eenig gewigt - want ook zij kent de manier om zaken commissoriaal te maken - benoemde zij een ncommittee on mercantile library", een on gold statistics, trustees of the institution for the savings of merchants clerks, of the nautical school for the harbor of New-York, een board of commissioners of pilots, en een lid van the board of commissioners for licensing sailors-boarding houses or hotels $D e$ aard der werkzaamheden van al die commités blijkt uit hunne titels; alleen verdient vermelding dat het "committee of arbitration" belast is met de beslechting van "all "mercantile disputes which may arise between members of the "chamber, or by parties claiming by, through or under them, "may be referred by mutual agreement." Van hare beslissing wordt appel toegelaten tot een committee of appeal, bestaande uit den president, de beide rice-presidenten en den thesaurier der kamer, met den president van het committee of arbitration.

Behalve de onderwerpen van algemeen handelsbelang waren er ook vele van minder gewigt, waarin de handelsstand van NewYork belang stelde en waaraan de kamer als zijn vertegenwoordiger deel nam. Ik bedoel $b$. $v$. inschrijvingen voor liefdadige doeleinden, of voor erkenning van nationale verdiensten of ook voor wetenschappelijke reizen, als naar China, de ondersteuning van het verzoek der officieren van de U.S. Navy, tot verhooging van tractement, en andere diergelijke onderwerpen. Zij zond eene commissie om haar te vertegenwoordigen bij de begrafenis van Lincoln; zij zond in 1864 een afgeraardigde naar York tot bijwoning van het congres over de regeling der avarijkwestie, en in 1865 den heer Cyrus W. Field om deel te nemen aan het onderzoek van het Suez-kanaal. Zij stelde hare vergaderzaal open voor den Reverend J. C. Fletcher, die eene voordragt hield over het tot stand brengen van eene stoombootverbinding tusschen Brazilie en New-York en over het nut van deze onderneming, welke sedert September 1865 was in werking gekomen; voor den lieut-govemor Bross of Illinois, die over de ontwikkeling en de hulpbronnen der welvaart van Noordwestelijk Amerika sprak en menige bijzonderheid over die streek mededeelde.

Van die voordragten heeft de kamer in het verslag harer zittingen zeer breedvoerige mededeelingen gedaan. Van hare overige werkzaambeden nam zij daarin ook de besluiten op, doch van de discussien geeft zij zeer weinig weder, hetgeen des to meer te betreuren valt, naarmate het gewigtige onderwerpen geldt, als b. $\mathbf{v}$. 
het voorstel van den franschen consul-generaal te New-York, dat de kamer de aanneming ran het fransche maten- en gewigtenstelsel in Amerika zou bevorderen, of het voorstel van den voorzitter der kamer, den heer Abiel A. Low, tot verbetering der geldcirculatio door het vaststellen van eene bepaling dat 10, 15 of $20 \mathrm{pCt}$. der inkomende regten zouden betaald worden in papier, hetgeen dan an de circulatie moest worden onttrokken en vernietigd. Hij grondde dit voorstel op de omstandigheid dat de opbrengst dier regten verre overtrof hetgeen voor rentebetaling en amortisatie der schuld noodig is. Dit voorstel werd in handen eener commissie gesteld; haar rapport komt echter niet in dit verslag voor.

Een voorstel tot het bijeenroepen van eene nationale conventio om te beraadslagen over de middelen tot verbetering van den toestand der katoencultuur en daarbij de hulp van den Staat in te roepen, werd door de kamer te New-York verworpen, omdat zij deze hulp afkeurde en meende aan den natuurlijken loop van zaken het herstel van dien cultuur te moeten overlaten. Daarentegen toonde zij zeer veel belangstelling voor de bevordering der inzendingen van Noord-Amerika op de Parijzer tentoonstelling in 1867, zij trok zich deze zaak ernstig aan. Welke hare overtuiging van het belang dezer tentoonstelling voor Noord-Amerika is; blijkt uit een harer rapporten, wairin zij o. a. de wijze nagaat waarop de Ver. Staten aan dat groote nijverheidsfeest der bescharing kunnen deelnemen. „Elk onzer Staten kan zich daar als 't ware in zijne karakteristieke trekken vertoonen! Nieuw-Engeland zal er ongetwijfeld schitteren door de wonderen van zijn vindingrijken geest en van zijne magtige nijverheid! - New-York, de algemeene vervoerder voor de Broeder-staten, zal er de modellen van zijn schepen, - de voortbrengselen zijner zout-industrie, — zijn veestapel, - zijn reusachtige werktuigen van oorlog en vrede toonen; New-Yersey zende zijn mineralen rijkdom, zijn locomotieven en keurig nette rijtuigen; Pensylvanië het product van zijne „bergen van steenkool," zijn mineraal-olie en de vruchten zijner cyclopische smelterijen en ijzerwerken. Het kleine Delaware zende buskruid; Maryland zijn tabak, jyzer, chemicalien en uitmuntendo bouwmaterialen.

Het zonnige zuiden, dat zijne zwaarden thans weder tot ploegscharen versmeedt, toone den rijkdom en overloed zijner halftropische producten. Het groote noord-westen zende zijn koper, pelterijen, prachtige dennen - en de groote Vallei zelre, het toekomstig 
centrum der Amerikaansche magt, zende voor ieder deel harer magtige staten-groep, eenige monsters van die ontzaggelijke massa. granen, en der millioenen stuks vee in hare vlakten gevoed. De staten der Zuidzee zullen niet alleen hun goud, koper en rooral kwikzilver zenden, maar wel mogen zij Kaap Horn omvaren, om een der monster-monarchen hunner wouden, zoo oud als het christendom, te Parijs te gaan vertoonen; ons metaalrijk binnenland zende eene verzameling zijner veelvuldige ertsen ter bewondering van Europa, en eindelijk: dat het Mississippidal als levende getuigen inzende, verschillende planten zijner rijke cerealen in al hare verscheidenhed, met die gouden vruchten beladen, en daarnevens de heerlijke landbouwwerktuigen die den handenarbeid van millioenen vervangen, en die het zaaijen, het snijden en binnenbrengen van zulke enorme oogsten eerst mogelijk maken." (*).

(*) In this great exposition each of our States may in fact paint its own physical portrait - not on the canvas, nor in human linesments, but in the charactesistic exhibition of it peculiar products.

New England may and doubtless will abundantly display the marvele of her preeminently inventive genius, and her varied and "victorious indastry" on land and ses. New-York, the common carrier for her sister-States, may oxhibit the models of her ships, perhaps of her "canal-boats" - her precious salines - the remaius of her anoient forests - ber grazing industry - her gigantic engines of war and of peace, and the endless variety of her minor machineries and manufactures.

Now-Jersey may exhibit her peculiarly varied mineral wealth - her locomotipe ongines - her carriageo and equipments fit to be displayed in the Bois de Bonlogne; and last, not least, and as forming part of the "Serenth Group" the laxurions "mollusce" over which she, with New.York, excercises undipputed sway.

Pensylvania may point "not to her mines, bat to her mountains of coal" - the brosd and enduring basis of her wealth and power - already laying under tribute all the hearth-stones of the North; to the perfection and delicacy of her manufactures; to her new-found treasures in mineral oils, to the cyclopean energy of her furnaces, melting and moulding the iron of her "thousand hills"; while little Delaware may well display her gunpowder and Maryland her tobaceo, her iron, her chemicals, and the beanty and fineness of her building materials.

The "Sanny South" omerging from every oloud, and turuing her sworda into ploughshares, may exhibit the richness and abundance of her semi-tropical products, still so necessary to the welfare and comfort of the human race.

The great Northwest, looking out on the greatest of the lakes and the long interior chain of British waters, for which she furnighes the commercial ontlet, may show her copper, her fura, and the lofty pines around the erystal sources of our great continental river, winding its majestic course through twenty degrees of latitude to the cotton and sugar fields around the Galf. 
Zal Amerika dus niet schitteren op die tentoonstelling, gelijk andere landen wier fabrieksnijverheid zoo hoogen trap van ontwikkeling heeft bereikt, het zal zijn rijkdommen toonen en duidelijk kunnen maken dien wonderdadigen voorspoed dien bet na den oorlog zoo spoedig weder vertoond, de onuitputtelijke bronnen welke het met zoo groote veerkracht weder begonnen beeft te exploiteren.

De rapporten van de verschillende commissiën der Kamer zïn meest opgenomen achter het verslag harer handelingen, als $b$. v. dat over de tentoonstelling en het zeer lijvige rapport van Judge Marvin over de behandeling der arary-kwestie te York, waarbij eene vertaling is gevoegd van de wettelijke bepalingen in verschillende landen over de avary. Andere rapporten zijn in het verslag zelf ingelascht en daaronder komt vooral in aanmerking een rapport over de wharves and piers van New-York. Men ziet daaruit dat de tegenwoordige inrigtingen van los- en lardplaatsen niet slechts onvoldoende en ongeschikt zijn, maar zelfs gevaarlijk en zeer gebrekkig te achten. Houten steigers in het water uitgebouwd zijn de eenige losplaatsen die New-York aanbiedt. Ze rijn niet overdekt, niet alleen omdat het overdekken slechts bij uitzondering bij de wet wordt toegestann, maar omdat de steigers te zwak zijn om dit toe te laten. De

The great valley itself, the destined centre of American empire, may send forth from each of her mighty group of States, specimens of that gigantic mass of oereals, and of the millions of animals fed by those cereals, which soon must render it the dominant portion of the American Union.

The States of the Pacific will not only exhibit their gold, their copper and above all, their quicksilver, so providentially and abundantly garnered up to aid our mining interests, but they may circum-navigate Cape Horn lo carry to Paris one of the monster-monarchs of their forests coeval with the Christian era; while our vast metalliforous interior, with its parallel monntain ranges, prolongations of the Cordilleras of our sister continent, heavily laden with gold and silver - and its brosd and hitherto inacceasible basin, the laboratory of the continent in the early geologioul ages, with its immense deposits of saline and alkaline wealth, the brois of its fature commerce - will aend forth its glittering specimens for the admiration of Enrope.

From this precious, God given variety of physical resources our government, doubtleas, will wisely select, if all cannot be oxhibited.

En eindelijk "the Valley of the Mississipi must send out as living witnesses, vigorous stalks of its cereals in all their varieties, laden heavily with their golden fruit; and by their side, the wonder working agricultural machinery, doing the work of millions of men, and rendering possible the planting, and resping, and gathering in of harvests so enormous, 
onmetelijke handel van New-York moet zich met zwakke, smalle, onoverdekte steigers behelpen, die geene beschutting legen de zon, brand, vorst, storm of diefstal aanbieden. De pakhuizen en magazijnen liggen verre van het water; groote onkosten van vervoer enz. zijn daarvan het gevolg. Maar bovendien veroorzaken die steigers, digt op elkander gebouwd, opeenhoopingen van modder en vuilnis, welke zeer schadelijk voor de gezondheid zijn on hot water verondiepen.

Men wil in dien toestand verandering brengen. Dokken zooals to Londen of te Liverpool bestaan, kan men niet maken, want langs het water strekt de stad en het zoude te groote schatten kosten, daarvoor de bestaande huizen en gebouwen weg te breken. Maar nu wil een "New-York Pier and warehouse company”, volgens een plan van den ingenieur J. Burrows Hyde, steigers in het water bouwen op jizeren tubulaire met metselwerk gevulde kolommen en daarop ijzeren pakhuizen, vijf verdiepingen hoog, waarvan de onderste open, om als algemeene losplaats te dienen. Elk pakhuis zal van eene stoommachine worden voorzien tot het ophijschen der goederen, tevens geschikt om, in geval van brand, de brandspuit in beweging te brengen.

De voordeelen van dat plan zijn duidelijk genoeg; voor den handel levert het groote besparingen op en vermindert de risico van beschadiging der gooderen. Doch vooral voor de stad zelve schijnt het zeer noodig te zijn en eene verbetering van den toestand aan den waterkant te beloven die thans zeer gebrekkig is. De staat New-York zelve kan het plan niet uitvoeren, belast als hij is met een schuld van 50 millioen dollars, terwijl hij reeds jaarlijks 18 millioen doll. van de burgerij heft. Daarentegen ondervindt de bovengenoemde company groote moeijelijkheden en vertraging voor de uitvoering harer plannen in verschillende kwestien welke betrekkelijk den eigendom der steigera en het toezigt daarop uit te oefenen, zijn gerezen.

Twee derde van het boek wordt ingenomen door de handelingen en de rapporten der kamer; men kan daarin menige bijzonderheid vinden, maar toch moeten zij onderdoen in belang voor het laatste gedeelte dat de bijzondere verslagen over vele takken van handel bevat, en rijk is aan statistieke opgaven. Vooral deze laatste verdienen de aandacht, ze geven zoo volledige inlichtingen over de beteekenis van New-York's handel en zijn aandeel in den handel van Noord-Amerika. Ik meen dan ook niet beter te kunnen doen dan eenige dier tabellen mede te deelen en daaraan eenige op- 
merkingen welke het verslag ter opheldering van de cijfers oplevert, te doen voorafgaan.

In het algemeen kan men zeggen dat New-York voor drie vierde in de handelsbeweging der Vereenigde Staten deel neemt; gedurende den oorlog was dit aandeel misschien nog veel grooter, omdat toen de zuidelijke havens gesloten waren. Reeds dadelijk bij den vrede gevoelde dan ook New-York daarvan de gevolgen, voornamelijk in de uitvoeren, als van katoen enz. Zijne invoeren waren toen buiten alle verhouding tot die van andere plaatsen.

De geschiedenis van den handel in 1865 was gunstiger dan in de vorige jaren; de in- en uitvoeren waren grooter, maar ook de fluctuatien van de prijzen waren veel minder sterk. Dit was het gevolg van meerdere kalmte in de rijzing en daling van het goudagio. Hoewel van de prïzen zeer uitvoerige opgaven voor elke maand van alle artikelen worden gegeven, kan het echter de moeite niet beloonen daarvan vergelijkingen te maken. Voor hunne juiste beoordeeling moet men telkens op den stand van het goudagio letten en dit veroorzaakt een moeitevollen arbeid.

De suiker welke te New.York wordt aangevoerd komt vooral uit Cuba, van waar in 1865196227 tons kwamen, en van PortoRico 15.926 van den totalen invoer van vreemde suiker ad 228.241 tons. Sedert den afval van Louisiana, is de invoer van vreemde suiker reel vermeerderd, vooral ten behoeve van westelijk Amerika dat vroeger zooveel Louisiana suiker verbruikte. Er wordt veel sugar-house syrup voor huishoudelijk gebruik en stroop ran de sorgo in plaats van suiker gebezigd. De aanplant van de sorgo werd in Maryland, Delaware, Pensylvania, Now-Jersey en NewYork aanmerkelijk uitgebreid.

De totale invoer van vreemde suiker in de Vereenigde Staten bedroeg in 1865362.243 en in $1864,214.099$ ton, terwijl die to New-York in 1865228.241 en in 1864 139.127 ton bedroeg. De invoer in de Vereenigde Staten overtrof zelfs nog dien van het jaar 1860, toen 341.532 tons waren ingevoerd.

Van Melasse bedroegen de invoeren 35 millioen gallons in 1865 en 30 millioen in 1864 voor de Vereenigde Staten, waarvan 16t en $13 \frac{1}{2}$ millioen gallons in die jaren te New. York kwamen. In den invoer van melasse namen vooral Boston, Portland, Philadelphia deel, elk voor $\frac{1}{3}$ van de hoeveelheid welke New-York alleen annvoerde.

Negen tiende van de koffij welke in Amerika gebruikt wordt, komt uit Brazilië; onder de overige landen welke het laatste tiende 
leveren, stond Java en Sumatra in 1864 boven aan met 6.384,908 pd., in 1865 leverden zij echter slechts $178.000 \mathrm{pd}$.

In 1865 werden te New-York $c_{a} 113$ millioen en in 1864 114 i millioen ponden koffij arngeroerd; in de Vereenigde Staten 133! en 145 millioen in die zelfde jaren tegen ca 186 millioen in 1860 .

Voor de consumtie werden in de Vereenigde Staten afgeleverd 128 millioen ponden koffij tegen 109 millioen in $1864, c_{\mathrm{n}} 80$ mill. in 1862, 177 mill. in $1860, e_{\mathrm{n}} 228$ mill. in 1859 on 251 mill. in 1858. Men kan hiernaar beoordeelen hoezeer de koffijhandel gedurende den oorlog door de zware belasting gedrukt was. Om het aandeel van de groote handelssteden der Vereenigde Staten in hunnen totalen handel te overzien, behoeft men slechts den navolgenden staat van invoer van koffij te raadplegen; het leeuwenaandeel van New-York blijkt darait al zeer duidelijk.

\begin{tabular}{|c|c|c|c|c|c|c|c|}
\hline $\begin{array}{l}\text { Te New-York, } \\
\text { "Boston } \\
\text { "Philadelphia } \\
\text { "Baltimore } \\
\text { "New-Orleang } \\
\text { Anderé haveno }\end{array}$ & $\begin{array}{c}\text { zakke } \\
" \\
" \\
"\end{array}$ & $\begin{array}{l}\text { balen enz. } \\
" \\
" \\
" \\
" \\
"\end{array}$ & $\begin{array}{l}: \\
: \\
: \\
: \\
:\end{array}$ & : & \begin{tabular}{rr} 
& \multicolumn{1}{c}{1865} \\
$\cdot$ & 726.856 \\
$: \quad 10.176$ \\
$: \quad 24.044$ \\
$: \quad 85.242$ \\
$: \quad 14.509$ \\
$: \quad 1.514$
\end{tabular} & $\begin{array}{r}1864 \\
817.299 \\
80.104 \\
69.626 \\
96.909 \\
172 \\
1.779\end{array}$ & $\begin{array}{r}1863 \\
386.742 \\
31.688 \\
11.668 \\
75.599 \\
\overline{\mathbf{2 . 6 8 3}}\end{array}$ \\
\hline & & & Totaal & & 862.341 & 15.889 & 508.275 \\
\hline
\end{tabular}

De koffijhandel was in 1865 te New-York zeer levendig, omdat het Zuiden zich daar voorzag, terwijl het vroeger regtstreeks uit de productielanden zijn koffij had betrokken; in 1857 hadden de aanvoeren to New-Orleans zelfs die te New-York overtroffen.

Van de invoerartikelen zijn de manufacturen voor Amerika van overgroot belang. Bij het begin van den oorlog daalde die invoer in eens tot op de helft van het gemiddeld eijfer van vroegere jaren, maar zij nam allengs weder toe. In 1865 was hij zelfs veel belangrijker dan in 1857 en 1858 , jaren van buitengewoon levendigen handel, voornamelijk wegens de vraag naar manufacturen van het zuiden, maar ook wegens de algemeene schaarschte.

De invoer van zijden goederen heeft door den oorlog het meest geleden, daarentegen nam die van wollen goederen meer toe, wairschijnlijk ten gevolge van de vervanging in het gebruik van de eerste door de laatste.

De hooge regten op den invoer moesten ten voordeele van de Amerikaansche fabriekanten strekken; zij schijnen echter weinig gebaat te bebben. Voor 1856 tot 1860 was de wararde der ingevoerde manufacturen gemiddeld 91 millioen dls. jaarlijks. Door den oorlog verloor New-York $\frac{1}{3}$ van zijne afnemers van manufacturen. Wanneer dus de invoer gemiddeld 61 millioen hadde 
bedragen, kondeu de Amerikaansche fabriekanten nog niet geacht worden te hebben gewonnen; maar het gemiddeld oijfer voor die jaren was 66 millioen; zij wonnen er dus niet bij.

$\mathrm{Bij}$ de beoordeeling dezer eijfers verlieze men echter niet uit het oog, dat de prijzen der manufacturen zoo sterk zijn gerezen en dus een hoogere waarde van invoer nog geen vermeerdering van verbruik aantoont.

Onderstaande tabel geeft een overzigt van den invoer van ma. nufacturen te New York in de laatste 17 jaren.

WAARDE VAN DEN INVOER YAN MANUYACTUREN TE NEW-YORE. (in millioentallon dollars.)

\begin{tabular}{|c|c|c|c|c|c|c|}
\hline & Wollen. & Katoenen. & Zijden. & Linnen. & Verschillende. & TotaAl. \\
\hline 1849 & $11^{8}$ & $6^{3}$ & $15^{2}$ & 47 & $3^{9}$ & $42^{3}$ \\
\hline 1850 & $16^{\mathrm{b}}$ & 11 & $20^{2}$ & $7^{5}$ & $2^{2}$ & 579 \\
\hline 1851 & 152 & 11 & 234 & 67 & 41 & 606 \\
\hline 1852 & 161 & 113 & 220 & 71 & $4^{n}$ & 622 \\
\hline 1858 & 282 & 168 & 8411 & 87 & 57 & 934 \\
\hline 1854 & 218 & 156 & 275 & 72 & 58 & 79.1 \\
\hline 1855 & 191 & $1]^{2}$ & 234 & 60 & $5^{\circ}$ & 668 \\
\hline 1856 & 2B1 & $10^{9}$ & 287 & 87 & 72 & 818 \\
\hline 1857 & 249 & 174 & 276 & 60 & $6^{6}$ & 880 \\
\hline 1858 & 182 & 181 & 182 & 59 & 41 & 591 \\
\hline 1859 & 373 & 247 & 836 & 111 & 62 & 1131 \\
\hline 1860 & 365 & 179 & 349 & 70 & 67 & $101^{\circ}$ \\
\hline 1861 & 166 & 71 & 183 & 38 & $2^{8}$ & 488 \\
\hline 1862 & 257 & 85 & 114 & 76 & $2^{n}$ & 56 \\
\hline 1868 & 296 & 79 & 154 & $10^{3}$ & 37 & $67^{2}$ \\
\hline 1864 & 814 & 84 & 161 & $11^{6}$ & 30 & 71 \\
\hline 1865 & 36 & $15^{3}$ & $20^{5}$ & 154 & 44 & $91^{\prime}$ \\
\hline
\end{tabular}

$\mathrm{Na}$ de granen is petroleum tegenwoordig het gewigtigste artikel van uitvoer. In 1865 bedroeg de totale uitroer uit de Vereenigde Staten bijna 30 millioen gallons tegen $c^{a} .11$ millioen in 1862 en $1.112,476$ gallons in 1861 . En in 1866 van 1 Januarij tot half November steeg hij tot 56 mill. gall. Het aandeel van New-York in dien uitvoer nam zeer af, ten gevolge van de vermeerdering van de uitvoeren van Philadelphia; veel werd echter uit Philadelphia voor New-Yorksche rekening uitgevoerd.

De oude bronnen te Oil.Creek gaven aanmerkelijk minder, daarentegen nam de opbrengst te Pithole sterk toe en dekte het deficit volkomen. Men schat de geheele productie tegenwoordig op 10,000 vaatjes dagelijks. De prijzen welke voor den uitvoer besteed werden, leverden goede resultaten. (*)

Onderstaande tabel (in millioentallen gallons, van $\mathbf{4 0}$ in het vat) geeft eenig overzigt van de uitvoeren van petroleum uit de ver-

(*) Men vindt eene besohrijving der potroleum-winuing Economist, 1866, p. 306 \%. 
schillende havens van Amerika, benevens van eenige der voornasmste havens van bestemming.

\begin{tabular}{|c|c|c|c|c|}
\hline & New-York. & Philadelphia. & $\begin{array}{l}\text { Boslon, } \\
\text { Baltimore en overige } \\
\text { havens. }\end{array}$ & $\begin{array}{c}\text { Tolpal } \\
\text { in millioenen } \\
\text { gallons. }\end{array}$ \\
\hline 1861 & 11 & - & 7 & - \\
\hline 1862 & 67 & $2^{8}$ & $1^{3}$ & $10^{8}$ \\
\hline 1863 & $10^{5}$ & 54 & $3^{3}$ & $28^{2}$ \\
\hline 1864 & 213 & 77 & 28 & 318 \\
\hline 1865 & $14^{6}$ & $12^{5}$ & 27 & 298 \\
\hline
\end{tabular}

De voornaamste uitvoeren van petroleum waren (in duizendt. gallons).

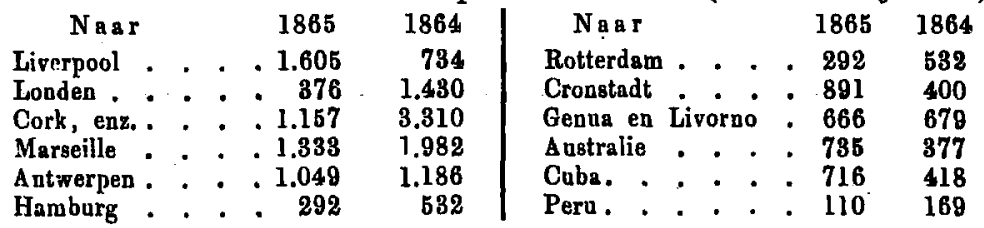

Van tabak waren in Amerika nog belangrijke voorraden, opgehoopt gedurende den oorlog, vooral door den oogst van 1863, die een van de grootste oogsten sedert vele jaren was. Zoo werd de oogst van Kentucky in 1863 geschat op ca. 114 millioen pd., in 1864 op ca. 57 millioen en voor 1865 op ruim 51 millioen pd.

De handel was over het algemeen weinig levendig; de kwestie der belasting op de tabak blijft den planter en den fabriekant dreigend boven het hoofd hangen.

Sedert April werd tabals bijna uitsluitend tegen goud verhandeld, daardoor waren de prijzen zooveel vaster.

De uitroeren uit Richmond bedroegen in 1865 naar Liverpool 2.671 geheele en 851 halve oxhoofden, naar Londen 2.495 en 1.279 halve, naar Frankrijk 5.835, naar Venetie 331 oxh., naar Bremen 2.349 en 8 halve, benevens 4.854 steelen en naar Halifax 45 oxhoofden, of in totaal 13.726 heele 2.139 halve oxhoofden tabak en 4.854 oxhoofden steelen.

De uitvoer van tabak uit New-York (in duizendl. pd.) bedroeg:

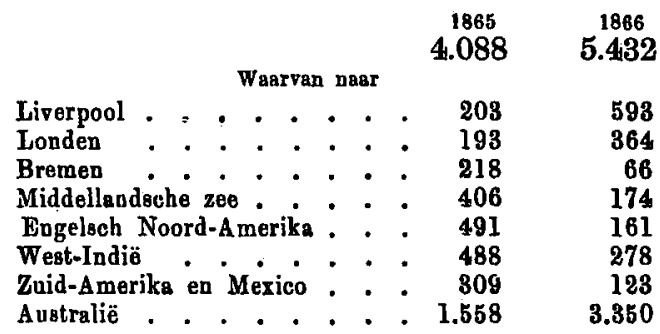

Voor. andere handelsartikelen verwijs ik meer in het bijzonder naar het verslag, en bepaal mij tot de aanteekening van onkele 
bijzonderheden. Zoo bedraagt de invoer van huiden te New-York gemiddeld $1 \frac{1}{2}$ millioen stuks per jaar, in 1859 bereikte die aanvoer het cijfer van 2.397,770. Ze zijn meest van de Buenos Ayres, Rio Grande en van de Montevideo en Orinocco soorten.

Opmerkelijk is de uitbreiding aan de fabriekage van schoenen to New-York gegeven; de leverantien voor het leger deden dezen tak van nijverheid zeer bloeijen. Ook wordt er zeer veel uitgevoerd voornamelijk naar Mexico waarheen $\frac{2}{3}$ der waarde of voor 417.834 doll. in 1865 werd verzonden. Men berekent dat thans te New York dagelijks 20,000 paar schoenen en laarzen gemaakt worden. De waarde van den uitvoer was in $1865681,616 \mathrm{dls}$, in 1864 748.122 en in 1863937.911 dls.

De kwaliteit van de schoenen, vooral van die voor het leger bestemd, liet echter zeer veel te wenschen over, en de verslaggever van dat artikel wordt bijna aandoenlijk wanneer hij zijn hoop te kennen geeft dat de eerlijkheid weder den boventoon in dien bandel zal aannemen.

Voor de walvischvangst waren in de Vereenigde Staten op 1 Januarij 1866 uitgerust 263 schepen tegen 276 op 1 Januarij 1865. Eene daarbij gevoegde tabel wijst de sterke vermindering van de vloot in de laatste jaren aan; men moet daarbij herinneren aan de verwoestingen der Shenandoah, die 23 schepen vernietigde.

De zetel der voornaamste reederijen is te New Bedford waar 164 van de 263 schepen te huis behooren.

De vangst van de North Pacific fishery bedroeg in 186536.415 vaten walvischtraan in 59 schepen of 617 vaten gemiddeld per schip. Daartegenover staat de vangst in 1855 met 217 schepen van 189,576 vaten ell van 1852 met 278 schepen 373,450 vaten traan.

Dat de handel in vijnen en sterke dranken te New-York gebukt gaat onder het hooge invoerregt, weten de Hollanders maar al te goed. Een regt van $2 \frac{1}{2}$ doll. per gallon op jenever, dat 3 à 4 maal de waarde van het artikel in 1861 vertegenwoordigt, moet 2 waar drukken. Maar toch wekt het verwondering dat de hollandsche jenever niet eens genoemd wordt in het verslag over dit artikel on dat daarvan invoer noch prijsnoteringen genoemd zijn.

Uitvoerige mededeelingen over de zout- en de ijzerproductie besluiten het verslag der kamer. In de Onondaga Salt Springs werden 6.385,930 schepels van 56 pond elk gemaakt, waarvan 1.886,760 door droogen in de zon en 4.499,170 door kunstwarmte. Het wordt meest in Amerika zelf verbruikt en weinig uitgevoerd, omdat het door de hooge werkloonen niet kan worden 
gemaakt voor een prijs die het met vreemd zout kan doen mededingen. Het invoerregt op vreemd zout is vrij matig.

De productie van het Onondaga zout leverde vroeger goede resultaten op, doch verminderde sedert de ontdekking vau zoutbronnen in de vallei van de Saginaw-river in Michigan, omstreeks 1862, vooral omdat deze bronnen gunstiger gelegen zijn voor het vervoer, en het zout daar met veel minder kosten kan worden asngemaakt. Sedert 20 Junij 1797 zijn de Onondaga Salt Springs in exploitatie; zij leverden 168.698.569 schepel in die 69 jaren. In 1862 was de productie het belangrijkst en gaf toen 9.053 .874 schepel.

Voor ijzer was de vraag in den aanvang van 1865 voor de behoette van het gouvernement zoo groot dat de Ameriksansche hoogovens op verre na niet genoeg konden voortbrengen. De aanvoer van buitenlandsch ijzer gaf toen geen goede rekening door de fluctuatie van de goud-agio, zoodat het Amerikaansche ijzer op de markt bijna uitsluitend in aanmerking kwam en hooge prijzen kon bedingen. $\mathrm{Bij}$ het einde van den oorlog werd die stand van zaken echter geheel veranderd en in den aanvang van den zomer werd zelfs in vele hoogovens het werk gestaakt. Later kwam de vorige levendigheid wel terug maar toen hadden de steenkoolproducenten het in hunne magt hunne prijzen op to drijven, zoodat het voordeel voor de ijzersmelterijen gering werd. Van buitensporige speculatien kan die handel in ruw ijzer in $\mathbf{1 8 6 5}$ het voorbeeld geven, op het laatst van het jaar kwamen or groote aanvoeren van ijzer uit Europa die met voordeel geplaatst werden.

De productio van alle soorten van ruw juzer in de Vereenigde Staten bedroeg in 1856910.466 tons van 2000 pond elk.

en in 1864 1.149.903 " " " "

Zij vermeerderde dus met $26 \mathrm{pCt}$. In 1864 werden

in het Lehigh district of Penn 214.093 tons ruw ijzer gemaakt.

" Schuylkill " " 112.806 ". " "

" Lower Susquehanna of

Pennsylvanie . . . 118.615

" " Upper Susquehanna district . . . . . . . 108.664

" " Eastern District, wasronder New. York, Massachusetts Connecticut enz.

Vereenigde Staten.

Of in het gebeel . $\frac{138.140}{684.319}$ tons ruw ijzer in de

De productie was in $1865 \mathrm{ca}^{\mathrm{a}} \cdot \mathbf{4 7 9 . 5 5 8}$

of . . $-\overline{204.460}$ tons minder. 
Gemiddeld werden voor ton 1 ijzer $2 \frac{1}{2}$ ton ijzer.erts en 2 ton steenkolen gebezigd.

De productie van ijzerstaven in de Vereenigde Staten wordt op 974.876 tons in 1864 geschat. Die van Staal op 18000 tons, waarvan $e^{*}$ de helft alleen te Pittsburgh.

De belasting op de productie van ijzer bragt 8.445.018.95 doll. op en op die van staal 723.819.68 doll. in het jaar van 1 Julij 1864 tot 30 Junï 1865.

Een tabel op pag. 100-103 van het verslag geeft de waarde op van de productie van jizerwerken in elken staat der Unie voor de beide jaren 1850 en 1860 , zoowel aan ruw ijzer als aan machinerien, landbouwwerktuigen enz. Daaruit ziet men dat in 1850 in de Vereenigde Staten voor eene totale waarde van 72.081.226 en in 1860 van 135.020 .990 doll. werd voortgebragt.

Ten besluite volgen hier eenige uittreksels uit de staten die an het eind van het verslag voorkomen.

INYORR EN VERBRUIK DER VEREENIGDE STATEN. - Wadide der vreemde goederen.

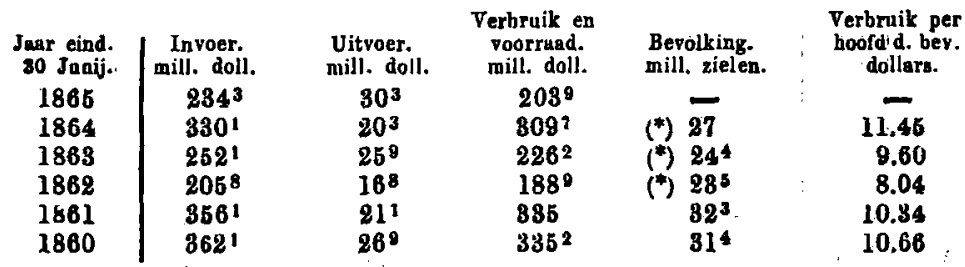

(") Gerand gedeelte der bevolking hetwelk van het ingevoerde verbruikte.

OITVOTR EN INYOER DER VEREENGGDE STATEN.

(in millioentallen dollars.)

\begin{tabular}{|c|c|c|c|c|c|}
\hline & & ( & Titong & Geld en & metaal. \\
\hline & $\begin{array}{l}\text { Uitvoer v. inlandischio } \\
\text { producten. }\end{array}$ & $\begin{array}{l}\text { Tolaal uitr. van inl. } \\
\text { prod, on vr. goed. }\end{array}$ & $\begin{array}{l}\text { Uitvoer van meel } \\
\text { en provinien. }\end{array}$ & yoer & Uitvoer. \\
\hline $\begin{array}{l}1865 \\
1864 \\
1865 \\
1862 \\
1861 \\
1860\end{array}$ & $\begin{array}{l}306^{3} \\
320^{2} \\
324 \\
213 \\
389^{7} \\
378^{1}\end{array}$ & $\begin{array}{l}386^{8} \\
840^{6} \\
360 \\
229^{9} \\
410^{8} \\
400^{1}\end{array}$ & $\begin{array}{r}105^{2} \\
110^{6} \\
1391 \\
119^{3} \\
94^{8} \\
45^{2}\end{array}$ & $\begin{array}{r}7^{2} \\
13^{1} \\
9^{5} \\
16^{4} \\
46^{3} \\
8^{6}\end{array}$ & $\begin{array}{l}544 \\
69^{3} \\
823 \\
86^{8} \\
29^{7} \\
66^{6}\end{array}$ \\
\hline
\end{tabular}

INVOER TE NEW-YORK UIT DEN VREEMDE.

(in millioentallen dollars).

\begin{tabular}{|c|c|c|c|c|c|c|}
\hline & Manufacturen & $\begin{array}{c}\text { Andere } \\
\text { koopmansgoed: }\end{array}$ & $\begin{array}{l}\text { Belaste } \\
\text { goederen. }\end{array}$ & $\begin{array}{c}\text { Tolvrije } \\
\text { goederen. }\end{array}$ & specie. & Totanl. \\
\hline $\begin{array}{l}1865 \\
1864 \\
1863 \\
1862 \\
1861 \\
1880\end{array}$ & $\begin{array}{l}91^{9} \\
71^{5} \\
67^{2} \\
56^{1} \\
- \\
-\end{array}$ & $\begin{array}{c}180^{6} \\
144^{2} \\
118^{8} \\
117^{1} \\
-\end{array}$ & $\begin{array}{r}212^{2} \\
204^{1} \\
174^{\circ} \\
149^{\circ} \\
95^{3} \\
201^{4}\end{array}$ & $\begin{array}{l}10^{4} \\
11^{7} \\
11^{8} \\
28^{2} \\
80^{3} \\
28\end{array}$ & $\begin{array}{c}21 \\
2^{2} \\
15 \\
13 \\
37 \\
85\end{array}$ & $\begin{array}{l}224^{7} \\
218^{1} \\
187^{\circ} \\
174^{\circ} \\
168^{7} \\
299^{2}\end{array}$ \\
\hline
\end{tabular}


De ontrangsten aan inkomende regten bedroegen te New-York:

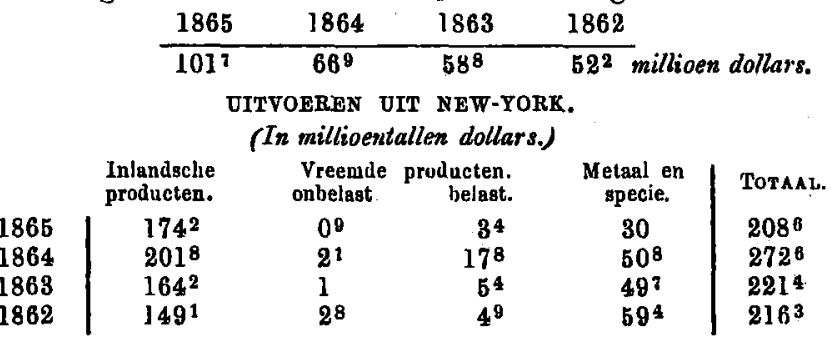

Uitroeren van Granen en Meelsoorten naar Groot-Brittannie en Ierland in de laatste 6 jaren, elk jaar loopende van 1 September tot ult. Augustus. (in ditizendtallen.)

Bloem, vaten. Meel, vaten. Tarwe, schepel. Graan, schepel.

\begin{tabular}{l|rrrr}
1865 & 170 & & 2.989 & 1.293 \\
1864 & 1.241 & $0^{1}$ & 16.498 & 717 \\
1863 & 1.479 & 1 & 23.167 & 10.334 \\
1862 & 2.672 & 1 & 25.754 & 14.084 \\
1861 & 2.561 & 4 & 25.553 & 11.705 \\
1860 & 717 & $0^{9}$ & 4.938 & 2.221
\end{tabular}

Uitvoer naar het Continent.

\begin{tabular}{l|cccc} 
& Bloem, vaten. & Rogge, schepel. & Tarwe, schepel. & Grann, schepel \\
1865 & 23 & 97 & 112 & 11 \\
1864 & 100 & 13 & 333 & 13 \\
1863 & 213 & 435 & 2,343 & 68 \\
1862 & 626 & 1.612 & 7.617 & 822 \\
1861 & 142 & 347 & 3.452 & 101 \\
1860 & 49 & & 178 & 19
\end{tabular}

In het jasr 1850 werden 853.330 .000 schepel diverse graansoorten in de Vereenigde Staten voortgebragt, in 1860 1.205.642.192 schepel.

TONNEMAAT DER VLOOT VAN NEW-YORK.

(In duizendiallen tonnen.)

\begin{tabular}{l|cc|c}
\multicolumn{5}{c}{ (In dzizendtallen tonnen.) } \\
& Begistered. & Enrolled and licenged. & Tot a a I. \\
1860 & 838 & 625 & 1464 \\
1861 & 912 & 626 & 1539 \\
1862 & 921 & 645 & 1567 \\
1863 & 846 & 777 & 1624 \\
1864 & 723 & 931 & 1654 \\
1865 & 471 & 751 & 1223 \\
Nieawe meting & 192 & 200 & 393
\end{tabular}

IN- EN UITKIARINGEN. - 1 Julij 1864-ult. Juxij 1865.

(in duizendlallen tonnen).

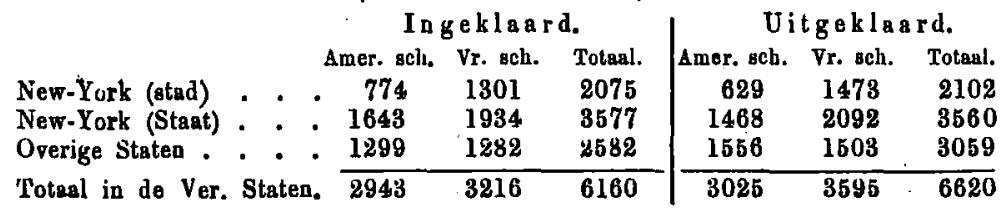

Uit vreemde havens zijn te. New-York in 1865 aangekomen 454 
stoombooten en 4,208 zeilschepen, of in het geheel $4,662 \mathrm{sch}$. tegen $5,4,87$ in 1862.

Daarpan waren stoombooten 157 en zeilschepen 1368 onder Amerikaansche vlag.

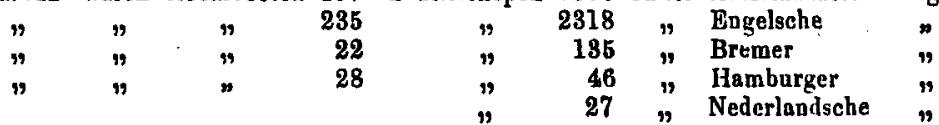

De kustraart leverde inklaringen van 1604 stoombooten en 6318 zeilschepen op, zoodat in bet geheel te New-York in 1865 zijn ingeklaard 12634 schepen.

De werkzaamheden van het Ner-York clearing house begonnen den 11 October 1853, en thans nemen 57 banken daarin deel. $\left({ }^{*}\right)$

Van 11 Octobor 1853 tot 1 April 1866 bedroegen de exchanges in totaal 136.284 millioen doll., de balances in totaal 6.202 mill. doll., te zamen 142.486 mill. doll.

In het eerste jaar bedroegen de exchanges 5.750 mill. en de balances 297 mill. doll. In 1865 de exchanges 26.032 mill. en de balances 1.035 mill. doll. In 1854 was 't gemiddeld cijfer per dag van de exchanges 19 mill. en van de balances 988.000 doll. In 1865 per dag van de exchanges 84 mill. doll. en van de balances 3 mill. doll.

De toestand der Vereeniging van Banken (Associated Banks of the city of Nero-York) was

(in duizendtallen doll.)

PASSIVA.

19 Junij 1858. 81 Manrt 1866.

Kapitaal . 67.041

Netto winst $\mathbf{7 . 5 3 1}$

Oml. bankbj. 7.080

Aan banken. 28.275

Aan depos. 74.806

Diverse. - 430

Total .. $\overline{185,166}$
80.770

23.042

26.954

36.304

252.961

1.125

424.660
ACTIVA.

19 Junij 1838. 31 Mrt, 1866.

Aau Discont, en beleen. . 118.249 163.458

Effecten........ 8.922 80.548

Hypotheken. ....... $440 \quad 281$

Vaste goederen ...... $5815 \quad 5.710$

Te vorderen van Banken. . $5.338 \quad 10.057$

Biljetton จ. andere Banken . 14.594 91.877

Specie ........ 31.704 9375

Wettig betaalmiłdel. ... - $\quad$ 71.104

Diverse........5 $51.606 \quad 296$

Spaarbanken in den Staat van New-York.

Deponito's. (in duizendt. doll.) Inbrengers.

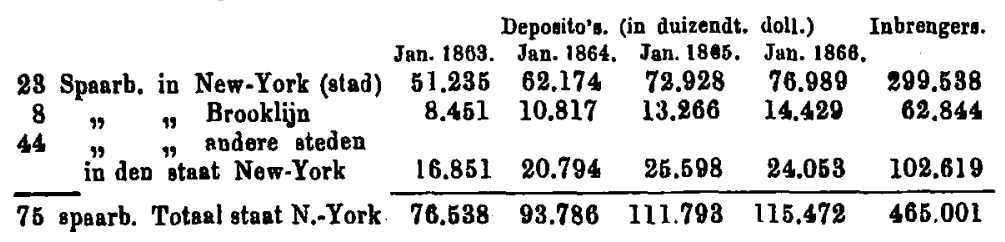

$\left(^{*}\right)$ Men zie over het New.Yorksche clearing-honse eene beschrijping, Economist 1865 , pag. 443, v. 
GERA APTE BCHEPEN.

\begin{tabular}{|c|c|c|c|c|c|c|}
\hline \multirow[b]{2}{*}{$\begin{array}{l}\text { Stoomochepen } \\
\text { Fregutten } \\
\text { Barken } \\
\text { Brikten } \\
\text { Schooners }\end{array}$} & Ton & maat. Warde & . 10 & $\begin{array}{l}\text { Van deze } \\
\text { Schepen. }\end{array}$ & $\begin{array}{l}\text { werden werk } \\
\text { Tonnemaat. }\end{array}$ & $\begin{array}{l}\text { K vernietigd: } \\
\text { Waarde. }\end{array}$ \\
\hline & $\begin{array}{r}6 \\
81 \\
83 \\
43 \\
70\end{array}$ & $\begin{array}{r}4.280 \\
73.748 \\
32.099 \\
10.409 \\
11.821\end{array}$ & $\begin{array}{r}985000 \\
14.140 .000 \\
6.825 .000 \\
1.930 .000 \\
1.666 .000\end{array}$ & $\begin{array}{r}4 \\
61 \\
74 \\
35 \\
61\end{array}$ & $\begin{array}{r}2.475 \\
53.557 \\
28.347 \\
8.476 \\
10.177\end{array}$ & $\begin{array}{r}575.000 \\
10.465 .000 \\
6.050 .000 \\
1.585 .000 \\
1.463000\end{array}$ \\
\hline & 283 & 32.307 & 25.546 .000 & 235 & 103.032 & 20.08 \\
\hline
\end{tabular}

Getal en suort der kaperschepen: 14 stoombooten, 5 barken, 1 brik, 5 schooners. Totanl 25.

Dollars.

De Alabama nam 69 schepen van 45.196 ton ter gezamenlijke wanrde 9.750 .000

De Floride " 36 " $" 19.870$.

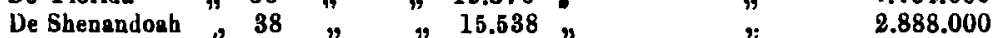

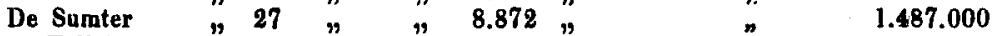

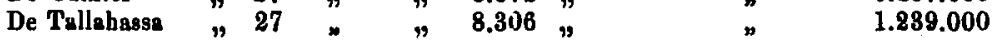

Uit een tabel van het aantal waloischvaarder's der Unie blijkt dat het getal en tonnemaat dier vartuigen over een vijftien tot twin. tigtal jaren sedert 1844 nagenoeg stationair bleef. In 1844 was het totaal 645 schepen (waaronder ook brikken en schooners) ter gezamenlijke bedrage van 200.147 tonnemaat; 1846 toont de hoogste tonnemast 233.189, voorts is er afneming tot 1851 (17.1.977); 1857 heeft weder 204.209 tonnemaat, en van dat jaar is er aanhoudend afneming tot 158.746 in 1861 en 68.536 in 1866 .

Do overige tabellen van het verslag bevatten: het cijfer van de openbare schuld der Vereenigde Staten in elk der jaren 1791 tot 1866, de in-en uitvoeren van goud en zilver te New-York in elke masnd van 1864 en 1865, de hoeveelheden gemunt goud zilver en koper in elk der jaren 1841 tot 1865 , de roorraden bij de diverse muntinrigtingen, de noteringen van bet goud-agio voor elken dag van 13 Januarij 1862 tot 30 April 1866, het getal der landverhuizers te New York in de laatste jaren aangekomen, met vermelding hunner nationaliteit, de koersen van den wissel op Europa, in 1865 bij het vertrek van elke stoomboot, de koersen der scheepsvrachten, der assurantie-premie en van eenige fondsen. 